\title{
Influence of External Factors on Results of Bushing $\tan \delta$ and Capacitance Measurements
}

\author{
J. BuCHACZ* AND Z. SzYMANSKI
}

ZPBE Energopomiar-Elektryka Sp. z o.o., Świętokrzyska 2, 44-101 Gliwice, Poland

The paper presents influence of external factors on results of bushing dissipation factor $\tan \delta$ and capacity measurements performed on not energized transformer as well as with operation voltage using on-line method. There are discussed methods and real cases of measurements, with emphasized differences in results interpretation. Conclusions and literature are summarized.

PACS: 84.37.+q, 77.22.Gm, 81.70.Ex, 84.32.Tt

\section{Introduction}

Bushing faults are one of the most frequent causes of transformer failures. On the base of CIGRE WG A2.43 data it is estimated that in most serious failures, connected with fire, this percentage reaches $56 \%$. Bushings diagnostics in Poland is based on measurements made during transformers periodical tests i.e. offline. In many cases it enables to reveal defects in early stages of development and to change faulty devices on time. Nevertheless these actions are not sufficient, especially for bushings which have been more than 20 years in service. This situation is probably caused by lack of differences in testing period of new transformers and transformers of long year exploitation. Currently transformers are tested every two or five years, depending of their power and voltage. As a result technical status of bushings is not evaluated in the period between tests. Because of that fact improvement in supervising of bushings technical status can be obtained either by increasing frequency of tests or introducing on-line diagnostics, performed by devices fixed on bushings.

Basic parameters of bushings measured offline and on-line are dissipation factor $\tan \delta$ and bushing's capacitance between line and test taps. Because it is necessary to compare results obtained using offline and on-line methods, their similarities and differences will be discussed as well as external factors that may influence results and connected with them decisions.

\section{Offline mode}

Measurements of bushings on not energized transformer, aimed for evaluation of $\tan \delta$ and capacitance are usually performed in two arrangements:

I - line tap to insulated test tap (Fig. 1a),

II - test tap to grounded line tap (Fig. 1b).

It is assumed that permissible $\tan \delta$ (in oil-impregnated-paper bushings) in arrangement " $\mathrm{T}$ " equals $0.7 \%$, at bushing temperature $20^{\circ} \mathrm{C}$, and capacitance $\mathrm{C}_{1}$

* corresponding author; e-mail: jerzy.buchacz@elektryka.com.pl

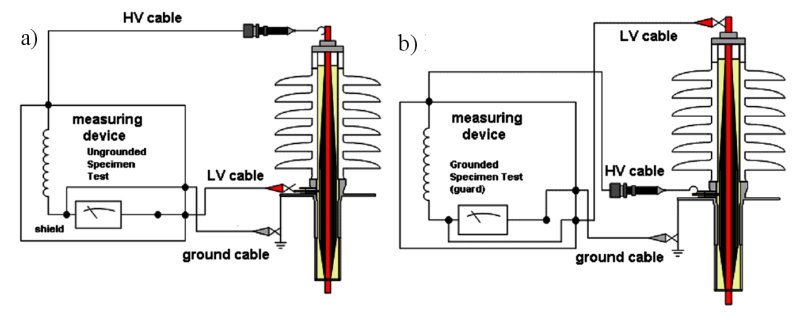

Fig. 1. Arrangements for measurements bushings tan $\delta$ and $\mathrm{C}$ : (a) I - UST, tan $\delta_{1}$ and $\mathrm{C}_{1}$ measurement, (b) II - GST, $\tan \delta_{2}$ and $\mathrm{C}_{2}$ measurement.

should not differ more than $10 \%$ from rated capacitance $[1,2]$. But in spite of long tradition of this measurement, there still exist difficulties in results interpretation, caused by influence of conditions at which measurement was performed.

Main factors influencing $\tan \delta$ results are:

- value of measuring voltage,

- temperature,

- moistness of bushing.

Voltage applied to bushing in measuring arrangement " $\mathrm{T}$ ' usually equals $2-12 \mathrm{kV}$, so is many times lower than rated voltage. This difference is meaningful for faulty bushings, but for bushings without defects voltage dependence of $\tan \delta$ is negligible (Fig. 2).

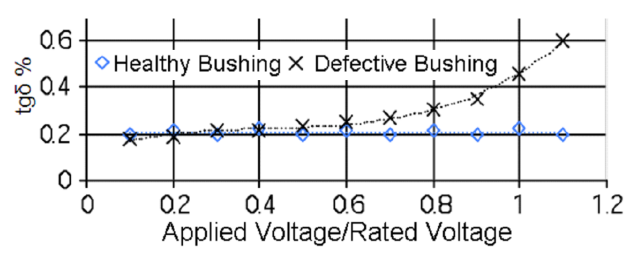

Fig. 2. Voltage dependence of $\tan \delta$ in good and faulty bushing. Reprinted with permission from Ref. [3].

In figure above "healthy" and faulty bushing do not reveal differences in $\tan \delta$ level with $10 \%$ to $20 \%$ of 
rated voltage, but differences increase with voltage. It means that some defects are not possible to be diagnosed by $\tan \delta$ measurement that enables applying $12 \mathrm{kV}$ maximum.

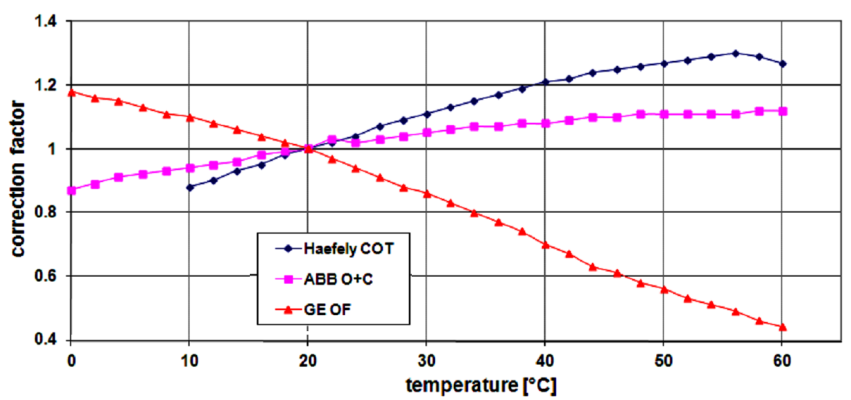

Fig. 3. Correction factors for $\tan \delta$ in different types of bushings. Data from Ref. [4].

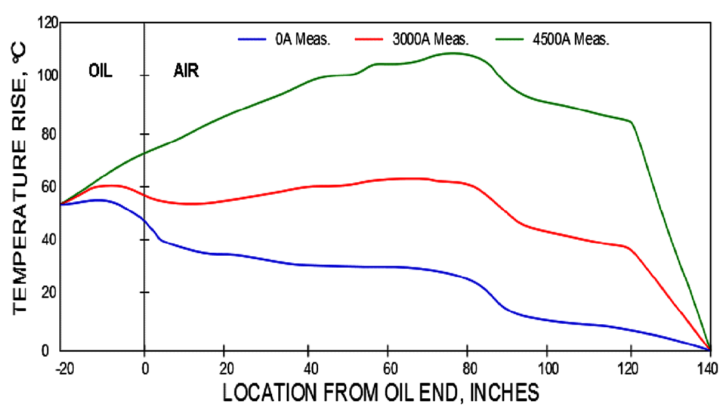

Fig. 4. Temperature distribution along bushing core. Adapted from Ref. [5].

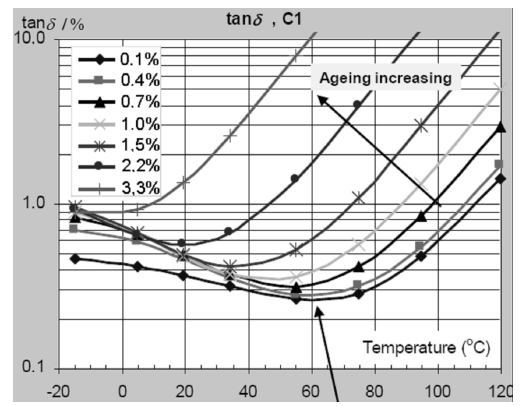

Fig. 5. Dissipation factors versus temperature with increase of moistness. Reprinted with permission from Ref. [6].

Temperature dependence of results can be taken into account by using correction factors (Fig. 3), which are sometimes given by manufacturers of dissipation factor meters, for chosen types of bushings [4], but there still exists a problem of appropriate temperature determination, because of its non-uniform distribution (Fig. 4).

Besides, $\tan \delta$ temperature dependence is strongly influenced by bushing moistness [6] (Fig. 5), whose influ- ence on dissipation factor at $20^{\circ} \mathrm{C}$ starts to be significant at $3 \%$ of moistness.

Water content in bushing insulation causes its accelerated deterioration and increases probability of fault.

\section{Methods of bushings measurements with load voltage (on-line mode)}

In on-line mode, evaluation of bushings technical status is based on measurements with using bushing test tap.

There are used two methods [7]:

- comparative (reference),

- sum of currents.

\subsection{Comparative method}

This method utilizes arrangement similar to the Schering bridge with second bushing of known capacitance and dissipation factor on the same voltage phase used as reference capacitor (Fig. 6).

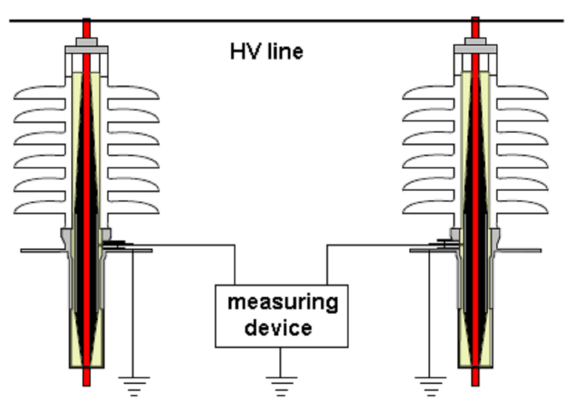

Fig. 6. On-line method with reference bushing.

There is another modification of comparative method, with voltage transformer used as reference object, and device calculates bushing $\tan \delta$ and capacity on the base of $\mathrm{HV}$ grid voltage, capacitance current and phase difference between current and voltage (Fig. 7).

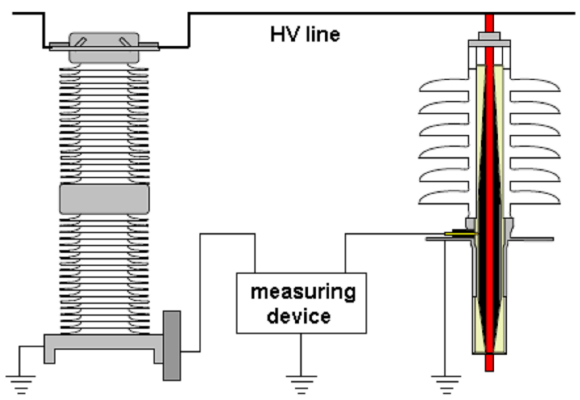

Fig. 7. On-line method with voltage transformer used as reference voltage source.

Comparative method enables measurements of single bushings and obtained results can be compared with $\tan \delta$ and capacitance values obtained offline. 


\subsection{Sum of current method}

In three-phase circuits with bushings having the same dielectric properties, vector sum of their currents should equal zero (Fig. 8).

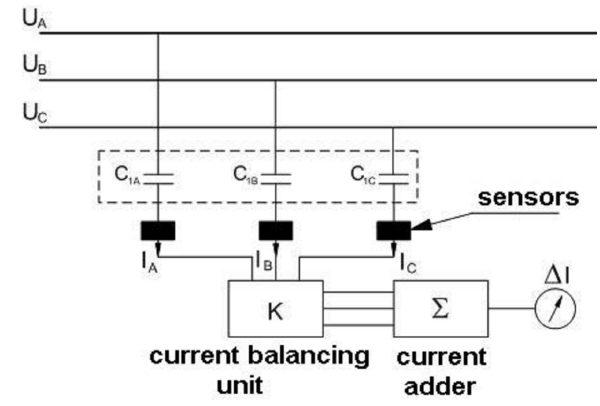

Fig. 8. Connection scheme of monitoring system using sum of currents.

Real bushings are always slightly different and phase voltages are not the same. If in the moment of putting on measuring system, sum of currents is not balanced to zero, every change of bushings capacitance and/or $\tan \delta$ will cause increase of sum of current vectors [8] called imbalance current. In sum of current method, amplitudes of bushings capacitance currents and their phase differences are used for calculations of factors corresponding to changes in bushings capacitance and $\tan \delta$ (Fig. 9).

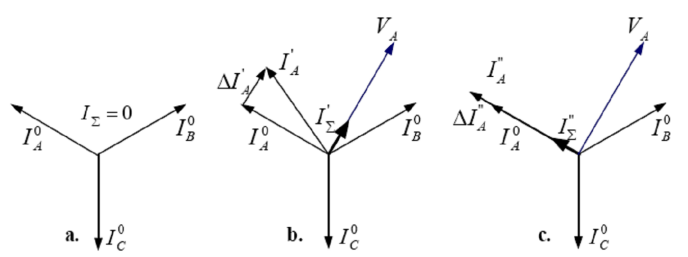

Fig. 9. Change of sum of current vectors: (a) sum balanced to 0 , (b) change of current $I_{A}^{0}$ caused by changes in phase $A$ bushing $\tan \delta$ change - new current $I_{A}^{\prime}$ (imbalance vector $I_{\Sigma}^{\prime}$ corresponds to change of $\tan \delta$ and is oriented as voltage vector $V_{A 0}$ ), (c) change of sum of current vector is caused by change of phase $A$ bushing capacitance (additional current $\Delta I_{A}^{\prime \prime}$ is perpendicular to voltage vector $V_{A}$; new sum of current vector $I_{\Sigma}^{\prime \prime}$ is oriented along current vector $I_{A}$ ).

In comparison with offline measurements or reference methods, sum of current methods needs less data to be available (Table I).

In spite of complicated calculations in data processing, sum of current method is most frequently used for bushing on-line diagnostics. It is caused by easy mounting - all elements of measuring device are situated on the transformer.

\subsection{Influence of external factors on measuring accuracy in on-line methods}

Main factors influencing measuring accuracy in reference methods are:
TABLE I

Values available during bushings measurements.

\begin{tabular}{|c|c|c|}
\hline Value & $\begin{array}{l}\text { Offline measurement, } \\
\text { reference method with HV } \\
\text { instrument transformer }\end{array}$ & $\begin{array}{l}\text { Sum } \\
\text { of current } \\
\text { method }\end{array}$ \\
\hline applied voltage ${ }^{*}$ & + & - \\
\hline $\begin{array}{l}\text { leakage current } \\
\text { phase angle }\end{array}$ & + & + \\
\hline $\begin{array}{l}\text { between voltage } \\
\text { and leakage current }\end{array}$ & + & - \\
\hline frequency & + & + \\
\hline
\end{tabular}

* Voltage applied to bushing in offline method is maximally several $\mathrm{kV}$, in on-line method it is rated voltage.

- changes of grounding voltage,

- systematic uncertainty of sensors mounted on bushings,

- bushing temperature.

Value and phase of grounding voltage in transformer neighbourhood are changing with time. They are dependent among others on load and interference with open-wire lines. Scheme of the equivalent circuit illustrating influence of grounding is shown in Fig. 10.

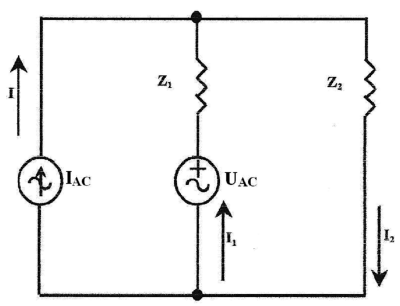

Fig. 10. Scheme illustrating grounding influence on measuring accuracy. $I_{\mathrm{AC}}$ - current source representing leakage current flowing through the bushing, $U_{\mathrm{AC}}$ - voltage source imitates grounding potential, $Z_{1}$ impedance of measuring sensor connected to the tap of tested bushing, $Z_{2}$ - input impedance of measuring instrument.

As it was mentioned in [3], change of grounding voltage phase angle in relation to a leakage current of $1^{\circ}$ causes increase in $\tan \delta$ about $0.067 \%$ (change of $5^{\circ}$ gives change in $\tan \delta$ of $0.335 \%$, respectively). Temperature and moistness influences on results in reference methods are similar as in offline, with additional influence of temperature difference of tested and reference bushings.

Sum of current method, because of its principle, compensates some unfavourable factors, like sensors systematic uncertainty and influence of grounding voltage, but is susceptible to other ones e.g.:

- changes in phase voltages,

- changes in phase angles between voltages. 


\section{Examples of interpretation of bushing in service measurements results}

Lack of differences in measured values $\mathrm{C}_{1}$ and $\tan \delta$ in relation to factory values unequivocally confirms good status of bushing, in opposite situation internal defects can be suspected. In such cases it is important to determine character of change that can point on a type or location of defect.

\subsection{Examples of offline measurements}

Bushing measurements are performed in different atmospheric conditions, which cause possibility of errors in evaluation of their technical condition. Table II presents results of such measurements. First tests were done at $13^{\circ} \mathrm{C}$ with high air humidity and obtained results exceeded permissible values. In order to check real technical status of bushings measurements were repeated in good weather at $15^{\circ} \mathrm{C}$, and technical judgment was done on the base of analysis of external conditions influence of tests results. It enabled restoring transformer operation that has been operating without defect for several years already, which confirms correctness of evaluation. Lack of this analysis and decision about second tests would result in putting transformer out of service and bushings change.

Results of measurements

TABLE II performed in different weather conditions.

\begin{tabular}{|c|c|c|c|c|c|}
\hline \multicolumn{6}{|c|}{ Measurement I (high air humidity), $13{ }^{\circ} \mathrm{C}$} \\
\hline Bushing type & Phase & Arrangement* & $\begin{array}{c}\mathrm{Up} \\
{[\mathrm{kV}]}\end{array}$ & $\begin{array}{c}\tan \delta \\
{[\%]}\end{array}$ & $\begin{array}{c}\mathrm{Cx} \\
{[\mathrm{pF}]}\end{array}$ \\
\hline \multirow{2}{*}{ OIP $145 / 275-800$} & \multirow{2}{*}{$2 \mathrm{~A}$} & $\mathrm{I}$ & 10 & 2.09 & 276.8 \\
\hline & & II & 2 & 2.51 & 1545 \\
\hline \multirow{2}{*}{ OIP $145 / 275-800$} & \multirow{2}{*}{$2 \mathrm{~B}$} & $\mathrm{I}$ & 10 & 0.95 & 300.9 \\
\hline & & II & 2 & 1.93 & 2015 \\
\hline \multirow{2}{*}{ OIP $145 / 275-800$} & \multirow{2}{*}{$2 \mathrm{C}$} & $\mathrm{I}$ & 10 & 1.15 & 303.4 \\
\hline & & II & 2 & 2.35 & 1651 \\
\hline \multicolumn{6}{|c|}{ Measurement II, $15^{\circ} \mathrm{C}$} \\
\hline \multirow{2}{*}{ OIP $145 / 275-800$} & \multirow{2}{*}{$2 \mathrm{~A}$} & $\mathrm{I}$ & 10 & 0.76 & 273.2 \\
\hline & & II & 2 & 1.00 & 1510 \\
\hline \multirow{2}{*}{ OIP $145 / 275-800$} & \multirow{2}{*}{$2 \mathrm{~B}$} & $\mathrm{I}$ & 10 & 0.61 & 300.7 \\
\hline & & II & 2 & 1.24 & 1997 \\
\hline \multirow{2}{*}{ OIP $145 / 275-800$} & \multirow{2}{*}{$2 \mathrm{C}$} & $\mathrm{I}$ & 10 & 0.77 & 302.2 \\
\hline & & II & 2 & 1.47 & 1618 \\
\hline
\end{tabular}

* I - measurement in arrangement line tap to insulated test tap, II - measurement in arrangement test tap to grounded line tap.

\subsection{Example of on-line measurements}

Continuous supervising of bushing technical status could be assured only by on-line measurements. Similarly as in offline mode, result reflecting dissipation factor, capacitance and leakage current are influenced by different external factors.

In the graphs created from the data collected from working bushing monitoring systems besides $\tan \delta$ and capacity $\mathrm{C}_{1}$ there are presented also changes in bushings temperature during registration. Changes in individual values are shown in Figs. 11, 12.

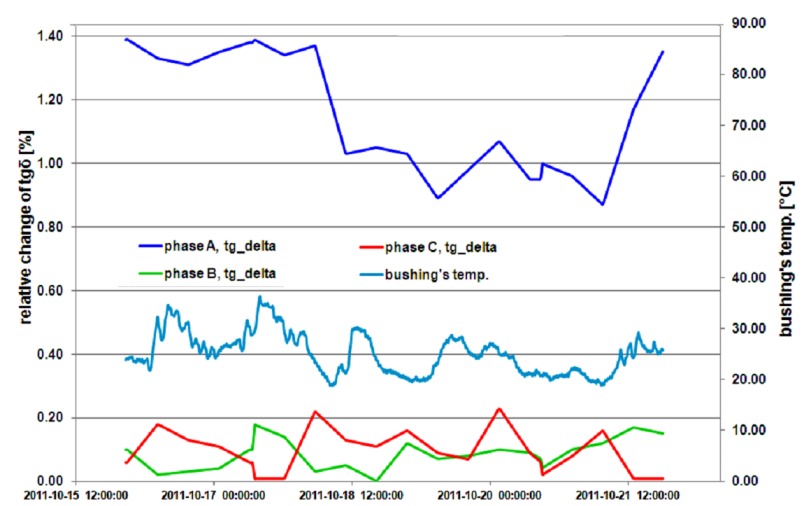

Fig. 11. $\tan \delta$ and evaluated bushings temperature versus time.

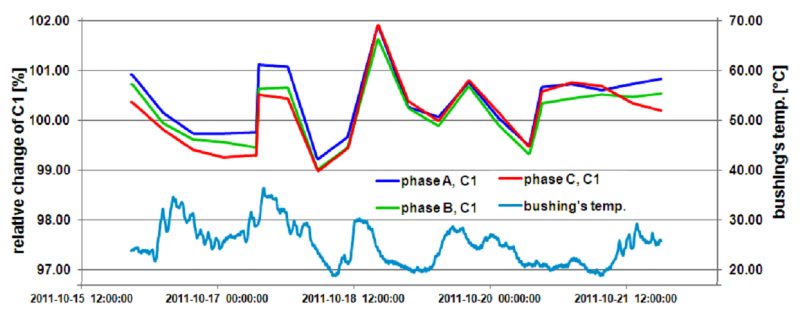

Fig. 12. Relative change in bushings capacitance and evaluated bushings temperature versus time.

Table III presents results collected from periodical tests of dissipation factor $\tan \delta$ and bushings capacitance with medium values evaluated on-line.

From comparison of periodical $\tan \delta$ measurements with on-line results we can conclude that they are similar for bushing mounted on phase A, but for remaining phases, in spite of significant differences in ambient temperatures, on-line are lower. In graphs we can also see influence of transformer load changes on $\tan \delta$ values. Figure 13 shows $\tan \delta$ after transformer de-energizing, that obtains higher values than during normal operation.
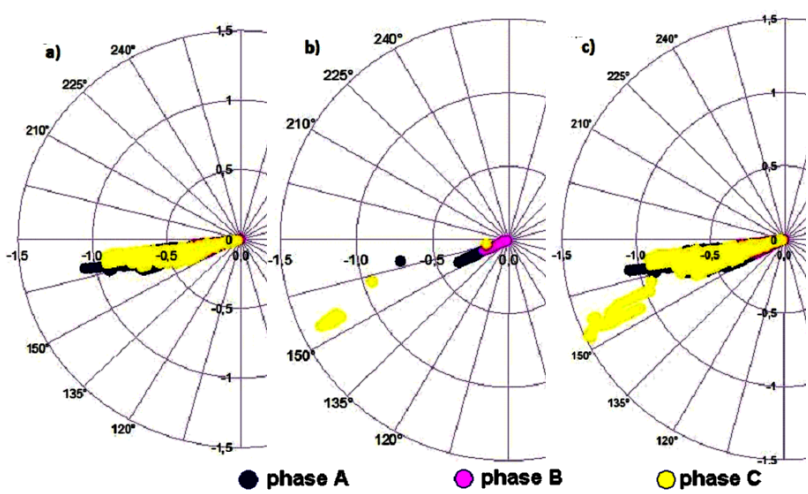

Fig. 13. Dissipation factor $\tan \delta$ versus phase angle of imbalance current: (a) during transformer operation, (b) after transformer de-energizing, (c) during next two months of operation. 
Temperature influence and transformer power on relative change of capacitance were not found. On the bases of analysis was revealed that during operation the changes take place in the range of $\pm 2 \%$. Dissipation factor of bushings in operation does not exceed $1.0 \%$, but during transformer de-energizing reaches $1.5 \%$. It means that values of dissipation factor considered as permissible for offline measurements are nor valid for measurements on-line. Proper evaluation and making technical decisions about bushings exploitation, assuming that all factors disturbing measurements are suppressed, new criteria for bushings tested on-line are demanded.

Results of periodical measurements of bushings $\tan \delta$ and capacitance.

TABLE III

\begin{tabular}{c|c|c|c|c|c|c}
\hline \hline Bushing type & Phase & Arrangement* & $\begin{array}{c}\mathrm{Up} \\
{[\mathrm{kV}]}\end{array}$ & $\begin{array}{c}\tan \delta \\
\left(\text { temp. } 20{ }^{\circ} \mathrm{C}\right) \\
\text { (offline) } \\
{[\%]}\end{array}$ & $\begin{array}{c}\tan \delta \\
\left(\text { medium temp. } 5{ }^{\circ} \mathrm{C}\right) \\
\text { (on-line) } \\
{[\%]}\end{array}$ & $C_{x}$ \\
\hline $\begin{array}{c}\text { OIP } \\
245 / 545 / 630\end{array}$ & $1 \mathrm{~A}$ & I & 12 & 0.84 & 0.8 & 244.5 \\
\hline $\begin{array}{c}\text { OIP } \\
245 / 545 / 630\end{array}$ & 1B & I & 12 & 0.67 & 0.2 & 224.9 \\
\hline $\begin{array}{c}\text { OIP } \\
245 / 545 / 630\end{array}$ & 1C & I & 12 & 0.93 & 0.5 & 233.4 \\
\hline
\end{tabular}

* I - measurement in arrangement line tap to insulated test tap.

\section{Conclusion}

Practical experiences confirm that in assessment of bushing status, it is very important to take into account conditions of measurement and factors influencing $\tan \delta$ and capacity values. It is valid both for offline and on-line methods. Additionally, using of on-line methods needs setting limits of measured parameters and developing principles of comparison with results obtained offline.

\section{References}

[1] Transformer Maintenance Guide, ZPBE Energopomiar-Elektryka, Gliwice 2012 (in Polish).

[2] K. Barczak, T. Pustelny, Z. Zycki, T. Blazejczak, Acta Phys. Pol. A 116, 250 (2009).

[3] Z. Berler, V. Sokolov, V. Prikhodko, D. Bates, in: Proc. Electrical Insulation Conf. and Electrical Manufacturing Expo., 2005, IEEE Conf. Publications - Digital Object Identifier: $\quad$ 10.1109/EEIC.2005.1566259, 2005, p. 61, http://www.ztzservices.com/files/onlinePFEIC2005.pdf.
[4] Guide "Doble Test Procedures", 72A-2244-01 Rev. B 10(04) (2007)

[5] D. Zeng, IEEE Trans. Power Delivery 14, 219 (1999).

[6] A. Mikulecky, "Transformer bushings reliability", presentation at CIGRE WG A2.43 3rd Meeting, Kyoto, 2011, in press.

[7] P. Svi, V. Smekalov, Transaction 12-106 in CIGRE - Group Transformers, 2009, Univ. XII, Paris, 2009, p. 263.

[8] M.Y. Lau, T. Schwartz, in: Proc. 71st Annual Int. Conf. of Doble Clients, Boston, 2004, p. 2, http://www.eaton.com/ecm/groups/public/@pub/ @electrical/documents/content/1077779936326.pdf. 